\title{
A statistical study on the recovery of pubalgic syndrome in football players
}

\author{
Catalin Ionite $^{1}$, Mariana Rotariu ${ }^{1 *}$, Marius Turnea ${ }^{1}$
}

Corresponding author: Mariana Rotariu, E-mail: rotariu29@yahoo.com

\begin{abstract}
According to pathology description, pubalgic syndrome affects increasingly more people, especially athletes practicing sports such as football, hockey, rugby, etc. Once this pathology has been established, in addition to pain in the pubic region, a decrease in mobility and muscle strength, it also induces changes in footprint and, implicitly, in the level of plantar pressure. The study was conducted on a number of 35 subjects, of which 30 healthy subjects and 5 subjects affected by pubalgic syndrome (pubis osteitis). The 5 football players affected by pubalgic syndrome (pubis osteitis) benefited from kinesiotherapy. All data, both initial and final, as well as the data recorded for the 30 healthy football players, were statistically processed and compared. The kinesiotherapeutic plan led to positive effects by reducing the symptomatology recorded at plantar level, and ANOVA tests helped in obtaining a qualitative contribution to the recovery program, as well as a socio-economic benefit for the patient.
\end{abstract}

Key words: pubalgic syndrome, kinesiotherapy, statistical analysis, postural test

\section{Introduction}

The football game has evolved considerably over the last decade, so players have to resort to "overtraining" to cope with the new standards imposed by the game. The "overtraining" that athletes use to compete consists of: increasing the number of weekly workouts, inadequate dosage of effort, weight before the recommended age, etc. All these "methods" used by athletes plus the high number of matches in both domestic and international championships have led to the emergence of new pathologies.

One of these new pathologies affecting football players is pubalgic syndrome (pubis osteitis). This condition was first described by Dr. Edwin Beer in 1924. Beer described it as a complication following surgery of the pubic symphysis, later migrating as an inflammatory process in athletes. In 2011, Demetrius E.M.L. wrote that this syndrome frequently occurs in football and accounts for 10$13 \%$ of all accidents every year (1).

Since the onset of the syndrome in football, most specialists have approached this problem from a pharmacological, imaging, radiological and surgical point of view $(2,3,4,5,6)$. A small number of specialists also addressed the issue of musculoskeletal impairment, syndrome classification, incidence and rehabilitation programs $(7,8,9,10,11,12)$. In 2012, Vijayakumar P. rehabilitated a soccer player affected by pubalgic syndrome (pubis osteitis) with the help of manual therapy and proprioceptive neuromuscular facilitation techniques, successfully used in the recovery of osteoarthritis and migraine cases as well (13, 14, 15). Ceatham S.W. contradicted Vijayakumar P. in 2016, writing that there is little evidence of the effectiveness of recovery and reintegration programs in competitive activity (16).

\section{Materials and methods}

The statistical study was performed on a group of 35 male football players ( 30 healthy subjects and 5 subjects affected by osteitis pubis), aged between 18 and 35 years. Both healthy and affected patients underwent initial and final testing, based on a postural test. Data were used from the article Assessment of Pubalgic Walking with the Help of a Podiatry Platform in Football Players (17). 
Patients affected by this syndrome benefited from personalized kinetic treatment:

- physical exercise;

- PNF techniques;

- massage.

The results were analyzed using the two ANOVA specific hypotheses: the null hypothesis (there is no relationship between variables), and the alternative hypothesis (relationships are established between variables, so they are dependent).

The results showed a correlation between the group of healthy players and those who benefited from the recovery plan.

The subjects were assessed by a postural test "Pedana OEM/DF, DISP MED. CLASSE I", along with "Dr. Foot Analysis 4.0" (Figure 1) $(17,18)$. Using them, data were collected on plantar footprint and plantar pressure for both the right and the left foot.

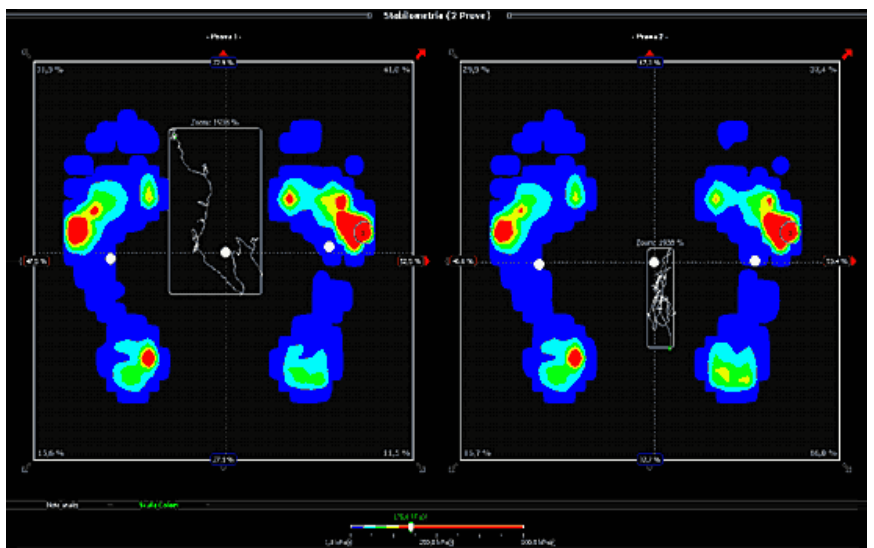

Fig. 1. Dr. Foot Analysis 4.0 - plantar surface, plantar footprint, pressure points together with the position of the center of gravity (16)

\section{Results}

After processing the data using the ANOVA test in the study Pubalgic Walking with the Help of a Podiatry Platform in Football Players, we identified that (Tables 1 and 2) (17):

Applying the statistical tests to regularize the experimental data led us to the following results:

- the sum of squares for both the left and the right foot is 573.975 , but with notable differences for weighted (568 for the right foot and 98.335 for the left foot), and deviation (21.163 for the right foot and 16.926 for the left foot);
- the number of degrees of freedom is equal for the right foot and the left foot;

- the major interest resides in $\mathrm{F}$; the value associated with the F-test is 10.214 with $\mathrm{p}$ $<0.243$ for the right foot, with a repeat of 1.147 with $\mathrm{p}<.532$ for the left foot, which leads us to the assumption that the weight is distributed on the left foot.

Figures 2 and 3 are graphical representations of Tables 1 and 2. In the figures mentioned below, it can be seen how the plantar footprint is inversely proportional to the pressure exerted at plantar level, namely:

- the right foot of healthy football players (Figure 2) - the plantar footprint is smaller compared to the left foot, but the pressure exerted at plantar level is higher for the right foot;

- the left foot of healthy football players (Figure 3) - the plantar footprint is larger compared to the right foot, but the pressure exerted at plantar level is lower for the left foot.

This can be explained by the fact that the football players used in the study Pubalgic Walking with the Help of a Podiatry Platform in Football Players are right-footed (17). While a larger left plantar footprint provides increased stability necessary for directional changes, kicks of the ball, etc., a lower plantar pressure favors the mobility of the segment for easy handling of the ball.

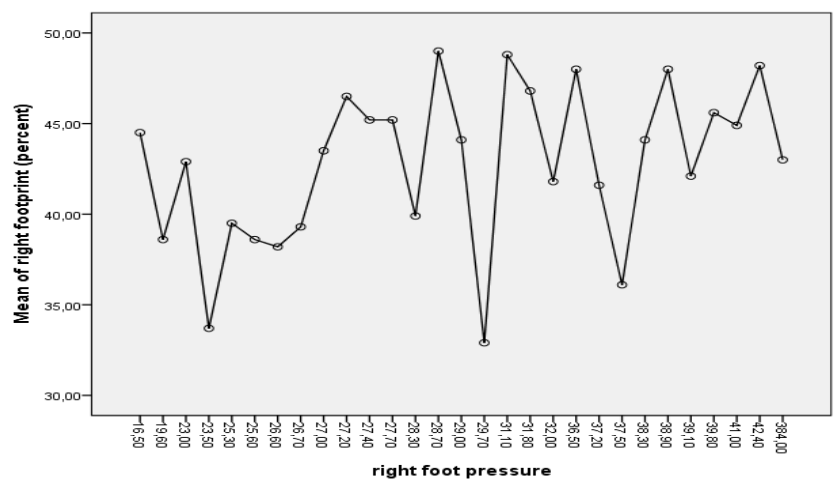

Fig. 2. ANOVA TEST - the correlation between plantar footprint and plantar pressure - right foot (healthy football players) 


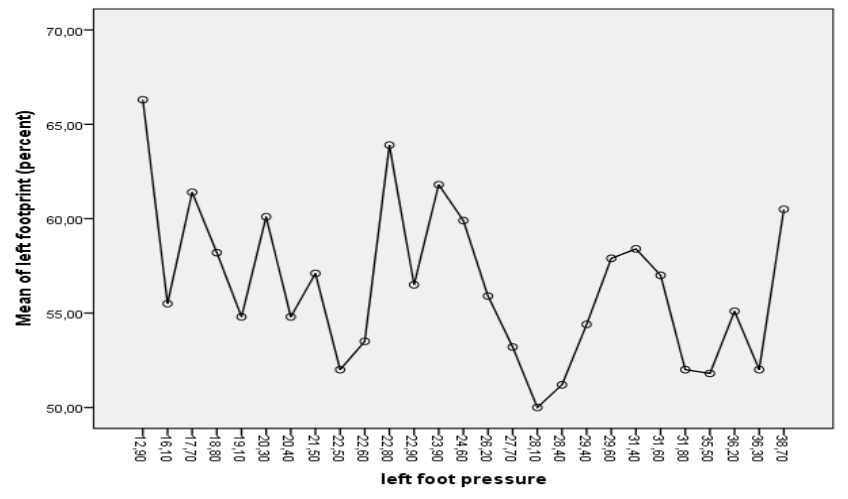

Fig. 3. ANOVA TEST - the correlation between plantar footprint and plantar pressure - left foot (healthy football players)

After kinetic treatment, the patients affected by pubalgic symptoms also had the final evaluation, and the data obtained are presented in Table 3.

Table 3 shows the differences obtained following the application of kinetic treatment for the right footprint, left footprint, right foot plantar pressure, left foot plantar pressure, and the center of gravity. The differences can be more easily observed in Figures 4 and 6 for the right foot and Figures 5 and 7 for the left foot.

If in healthy football players (Figures 2 and 3) the plantar footprint was inversely proportional to the pressure exerted at plantar level, with the development of the disease the ratio between the plantar footprint and the pressure exerted at plantar level became directly proportional (Figures 4 and 5) (initial testing). This is explained by the defense of the body, trying to limit as much as possible the contact of the right foot with the ground, thus modifying the general center of gravity.

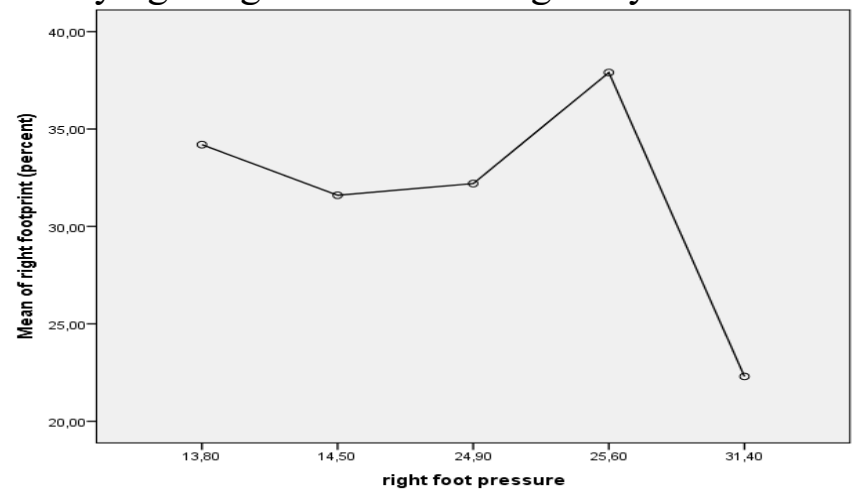

Fig. 4. ANOVA TEST - the correlation between plantar footprint and plantar pressure - right foot (initial testing of affected football players)

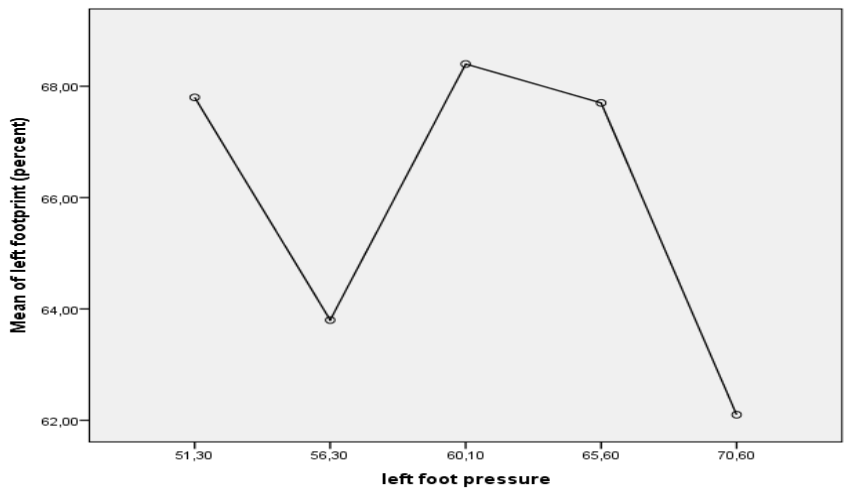

Fig. 5. ANOVA TEST - the correlation between plantar footprint and plantar pressure - left foot (initial testing of affected football players)

Following kinesiotherapy, as shown in Figures 6 and 7 (final tests), a tendency towards normalization occurred, with a change in the ratio from directly proportional to inversely proportional, like in the case of healthy football players.

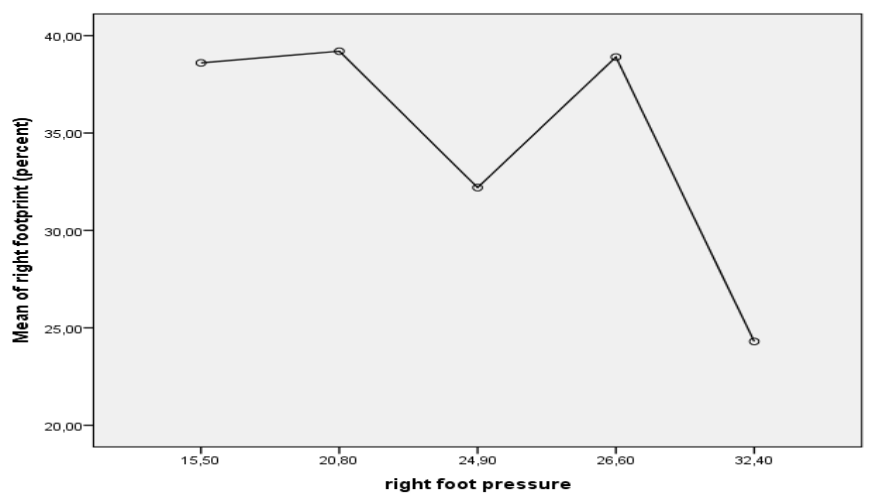

Fig. 6. ANOVA TEST - the correlation between plantar footprint and plantar pressure - right foot (final testing of affected football players)

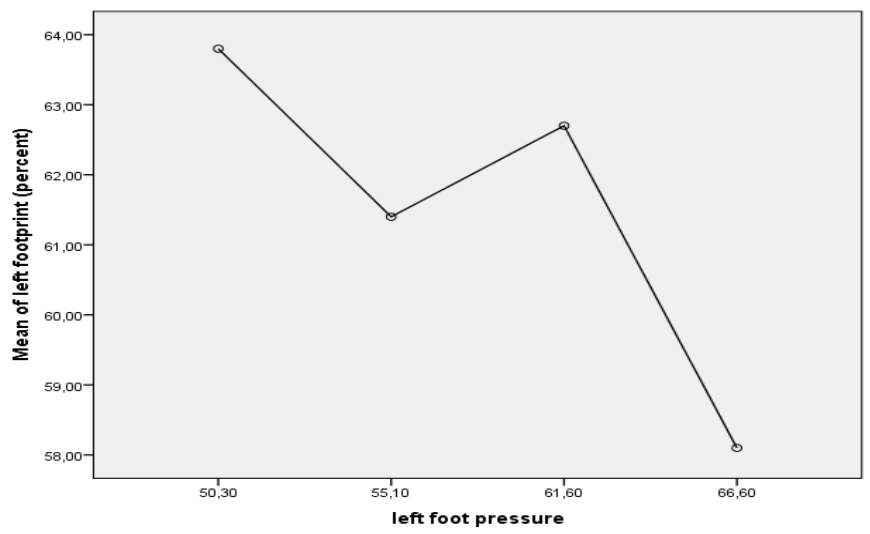

Fig. 7. ANOVA TEST - the correlation between plantar footprint and plantar pressure - left foot (final testing of affected football players) 


\section{Conclusion}

Following analysis, it can be said that the treatment plan had beneficial effects by reducing the symptomatology recorded at plantar level.

The parameters registered in the initial testing (affected players) changed after treatment, so that final testing parameters were close to the parameters recorded in healthy players.

Once established, the pathology causes changes in both footprint and plantar pressure.

The kinesiotherapeutic program led to a positive change in the final assessment compared to the initial assessment. After treatment, based on comparison and statistical processing of the data, a tendency towards normality in the affected players was evidenced.

ANOVA tests helped in the processing and interpretation of the data obtained, thus allowing a qualitative contribution to the recovery program, as well as a socio-economic benefit for the patient by decreasing the duration of treatment sessions and implicitly reducing the costs of the rehabilitation program.

\section{Informed consent}

An informed consent was obtained from the patients included in this study.

\section{Declaration of conflict of interests}

The authors declare that there is no conflict of interest regarding the publication of this paper.

\section{References}

1. Demetrius E.M.L. et al. Athletic Pubalgia (Sports Hernia). Clin. Sports Med. 2011 ;Vol. 30: 417-434

2. Genovese E.A. et al. Imaging assessment of groin pain, Musculoskelet Surg. 2013; Vol. 97: 109-116

3. Francesco G. et al. Osteitis pubis in profesional football players: MRI findings and correlation with clinical outcome. European Journal of Radiology. 2017; Vol. 94 :46-52

4. Mortensen H. Osteitis Pubis. The Journal of Urology. 1951; Vol. 66:412-417

5. McAleer S.S. et al. Management of chronic recurrent osteitis pubis/pubic bone stress in a Premier League Footballer: Evaluating the evidence base and application of a nine-point management strategy. Physical Therapy in Sport. 2015;Vol. 16: 285-299
6. Beatty T. Osteitis Pubis in Athletes, Current Sport Medicine Reports . 2012 ;Vol. 11,(2): 9698

7. Sheri L. A. et al. MR findings in athletes with pubalgia. Skeletal Radiol. 2001 ; 30: 270-277

8. Fricker A.P. et al. Osteitis Pubis in Athletes. Infection, Inflammation or injury? Sports Medicine. $1991 ; 12$ (4) :266-279

9. Johnson R. Osteitis Pubis, Sports Medicine Reports. 2003; 2: 98-102

10. Jim. M. et al. Groin Pain in Athletes. Sports Medicine Reports .2006; 5: 293-299

11. Pizzari T. et al. Prevention and management of osteitis pubis in the Australian Football League: A qualitative analysis. Physical Therapy in Sport. 2008; 9 ( 3): 117-125

12. Constantinescu V et al. Cortical modulation of cardiac autonomic activity in ischemic stroke patients. Acta Neurologica Belgica. 2016;16 (4): 473-480

13. A.C. Ionite et al. Hydrokinetotherapy combined with facilitation techniques in the recovery of osteoarthritis. Balneo Research Journal .2017; 8: 241-244

14. Vijayakumar P. et al. Multimodal physiotherapeutic management for stage-IV osteitis pubis in a 15-year old soccer athlete: A case report. Journal of Back and Musculoskeletal Rehabilitation. 2012; 25 (4), 225-230

15. A. C. Ionite et al. The use of combined techniques: Scottish showers, hot bath and manual techniques in the treatment of migraine headache. Balneo Research Journal .2017; 8 (4):245-247

16. Cheatham S.W. et al. The Effectiveness of Nonoperative Rehabilitation Programs for Athletes Diagnosed With Osteitis Pubis. Journal of Sport Rehabilitation .2016; 25:399-403

17. A. C. Ionite et al. Assessment of the Pubalgic Walking with the Help of Podiatry Platform at Football Players. The 13th International Scientific Conference eLearning and Software for Education. 2017;3:537-546

18. M. Rotariu et al. Statistical Analysis and Simulation of Orthostatic Position by Means of the Pedometer in Patients with Hyperkyphosis. Revista de Cercetare și Intervenție Socială .2017;59:209-221 
Table 1. ANOVA TEST - the correlation between plantar footprint and plantar pressure - right foot (healthy football players)

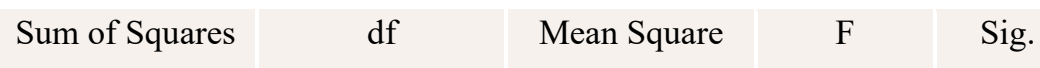

\begin{tabular}{|c|c|c|c|c|c|c|c|}
\hline \multirow{3}{*}{ Between Groups } & \multicolumn{2}{|c|}{ (Combined) } & 571.975 & 28 & 20.428 & 10.214 & .243 \\
\hline & \multirow{2}{*}{ Linear Term } & Weighted & .568 & 1 & .568 & .284 & .688 \\
\hline & & Deviation & 571.407 & 27 & 21.163 & 10.582 & .239 \\
\hline \multicolumn{3}{|c|}{ Within Groups } & 2.000 & 1 & 2.000 & & \\
\hline \multicolumn{3}{|c|}{ Total } & 573.975 & 29 & & & \\
\hline
\end{tabular}

Table 2. ANOVA TEST - the correlation between plantar footprint and plantar pressure - left foot (healthy football players)

\begin{tabular}{|c|c|c|c|c|c|c|c|}
\hline & & & Sum of Squares & $\mathrm{df}$ & Mean Square & $\mathrm{F}$ & Sig. \\
\hline \multirow{3}{*}{ Between Groups } & \multicolumn{2}{|c|}{ (Combined) } & 521.495 & 26 & 20.057 & 1.147 & .532 \\
\hline & \multirow{2}{*}{ Linear Term } & Weighted & 98.335 & 1 & 98.335 & 5.621 & .098 \\
\hline & & Deviation & 423.160 & 25 & 16.926 & .968 & .605 \\
\hline \multicolumn{3}{|c|}{ Within Groups } & 52.480 & 3 & 17.493 & & \\
\hline \multicolumn{3}{|c|}{ Total } & 573.975 & 29 & & & \\
\hline
\end{tabular}

Table 3. Initial and final evaluation of the affected group

\begin{tabular}{|c|c|c|c|c|c|c|c|c|c|c|c|c|c|c|}
\hline $\mathbf{S}$ & \multicolumn{3}{|c|}{ Apd (\%) } & \multicolumn{3}{|c|}{ Aps (\%) } & \multicolumn{3}{|c|}{ Ppd (kgf) } & \multicolumn{3}{|c|}{ Pps (kgf) } & \multicolumn{3}{|c|}{ SCg (cm $\mathbf{3})$} \\
\hline
\end{tabular}

*Legend: $\mathrm{S}=$ subjects, Apd = right footprint, Aps = left footprint, $\mathrm{Ppd}=$ right foot plantar pressure, $\mathrm{Pps}=$ left foot plantar pressure, $\mathrm{SCg}=$ center of gravity 